\title{
DiOITOS
}

Revista de Comunicación Digital

\section{Hybrid Media System: Politics and Power}

Andrew Chadwick

Oxford: Oxford University Press, 2013

272 páginas

Tomás Baviera Puig

tomasbaviera@gmail.com

Universidad Internacional de Valencia

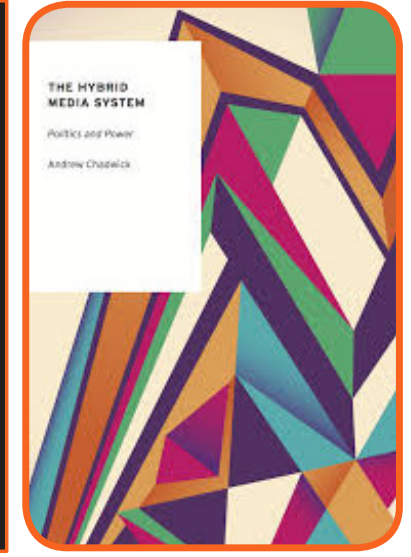

El libro The Hybrid Media System ha sido recientemente galardonado con el 2016 International Journal of Press/Politics Book Award. Entre los motivos que justificaron la decisión del jurado, se señaló lo siguiente: "Más y más investigadores insisten en que la investigación en comunicación política necesita innovación teórica para comprender adecuadamente un entorno cambiante de medios. Son pocos los que han intentado tales innovaciones. Andrew Chadwick es uno de ellos."

Esta apreciación se hace evidente desde las primeras páginas del libro. El autor tantea un nuevo marco teórico, con elegancia y humildad, siendo consciente del riesgo asumido al delinear tal innovación. Audacias así no suelen proliferar en el mundo académico, y todavía menos cuando esta valentía va unida a un notable rigor académico y a una lectura ágil y amena.

Andrew Chadwick es actualmente profesor de Ciencia Política en el college de Royal Holloway, de la Universidad de Londres, donde además codirige el área de la Nueva Comunicación Política. Desde esta posición ha analizado el complejo entramado de la comunicación política, fundamentalmente en el ámbito británico y estadounidense.

El texto presenta el concepto de hibridación en los tres primeros capítulos. A primera vista, puede parecer excesivo. Sin embargo, Chadwick se esfuerza por ilustrar este concepto tanto a nivel práctico como histórico, puesto que constituye la base de su propuesta.

La idea de hibridación permite enfocar el escenario mediático de forma integrativa. Una de las intuiciones clave del razonamiento de Chadwick es que el nuevo entorno ya no funciona con el dilema "una cosa o la otra", sino que más bien responde a un planteamiento aditivo de "una cosa y la otra". Podría resultar confuso aproximarse al sistema actual de medios con categorizaciones predefinidas. Chadwick no rechaza este enfoque sino que subraya que el nuevo "modo de pensar" del investigador ha de estar caracterizado más bien por una apertura que hibride lógicas distintas y en muchos casos contrapuestas. Por un lado se encuentra la lógica de los medios y por otra la 
lógica de la red, pero no están aparte una de otra sino que operan simultáneamente. De ahí el problema que se plantearía al tratar de entender con una lógica equivocada realidades cuyo dinamismo no respondiera a tales premisas. En comunicación política, acertar con la respuesta es casi más importante que plantear la pregunta.

El capítulo 4 probablemente constituya el núcleo de la propuesta de Chadwick. La lógica de los medios tradicionales gira en torno al "ciclo de noticias". Los medios poseen unas rutinas profesionales que establecen las pautas de trabajo y de emisión o publicación de noticias. Ahora, no obstante, el ritmo de publicación inmediato que permite la red y que demandan los usuarios ha alterado estos modos. Pero no solo eso: los procesos de interconexión propiciados por las redes sociales, unido muchas veces a las técnicas del marketing en red, obligan a los medios a tomar parte de esta lógica. Chadwick subraya con precisión el problema real de fondo: los marcos interpretativos están fuertemente determinados por cómo se articule en tiempo real la cobertura de un evento, tanto a lo largo del mismo como también inmediatamente después. Por eso Chadwick aboga por hablar de "ciclo de información política". En este nuevo marco continuo, resulta clave determinar el momento oportuno para publicar y encauzar el flujo continuo de información. Esta característica determina de raíz el dinamismo del sistema híbrido de medios.

La propuesta de Chadwick queda ampliamente documentada en el resto del libro. Los casos de WikiLeaks y de la campaña presidencial de Obama ilustran aspectos del ciclo de información política y los efectos de un uso efectivo de la hibridación de lógicas. Los dos últimos capítulos pretenden proporcionar normas para los medios y los agentes sociales en el actual entorno de comunicación política. Este "saber hacer" se transmite en el libro de forma muy pegada a la realidad. Chadwick toma como base numerosas entrevistas realizadas a diferentes actores de la comunicación política, fundamentalmente de Gran Bretaña. Llama la atención la variedad de los grupos entrevistados: periodistas, activistas sociales, partidos políticos y miembros de organismos gubernamentales.

La radiografía que Chadwick realiza del sistema de medios le sirve para caracterizar la nueva forma de poder. Éste ya no depende tanto de los medios de comunicación ni de los organismos políticos. Se podría afirmar que emerge también de la capacidad de relación e interconexión: "El sistema híbrido de medios muestra un equilibrio entre las lógicas más antiguas de transmisión y recepción, y las nuevas lógicas de circulación, recirculación, y negociación" (p. 208).

Este panorama de transformación de medios y del poder realza el valor del trabajo de Chadwick. La innovación teórica unida a la extensa documentación de casos contribuirán decididamente a que The Hybrid Media System sea un libro de referencia para la comunicación política en los próximos años. 